\title{
Risk allelic load in Th2 and Th3 cytokines genes as biomarker of susceptibility to HPV-16 positive cervical cancer: a case control study
}

K. Torres-Poveda 1,2, A. I. Burguete-García ${ }^{1}$, M. Bahena-Román', R. Méndez-Martínez³, M. A. Zurita-Díaz', G. López-Estrada ${ }^{4}$, K. Delgado-Romero ${ }^{5}$, O. Peralta-Zaragoza' ${ }^{1}$, V. H. Bermúdez-Morales', D. Cantú6,

A. García-Carrancá ${ }^{3,7}$ and V. Madrid-Marina ${ }^{1 *}$

\begin{abstract}
Background: Alterations in the host cellular immune response allow persistent infections with High-Risk Human Papillomavirus (HR-HPV) and development of premalignant cervical lesions and cervical cancer (CC). Variations of immunosuppressive cytokine levels in cervix are associated with the natural history of CC. To assess the potential role of genetic host immunity and cytokines serum levels in the risk of developing CC, we conducted a casecontrol study paired by age.

Methods: Peripheral blood samples from patients with CC $(n=200)$ and hospital controls $(n=200)$, were used to evaluate nine biallelic SNPs of six cytokine genes of the adaptive immune system by allelic discrimination and cytokines serum levels by ELISA.
\end{abstract}

Results: After analyzing the SNP association by multivariate logistic regression adjusted by age, CC history and smoking history, three Th2 cytokines (IL-4, IL-6 and IL-10) and one Th3 (TGFB1) cytokine were significantly associated with CC. Individuals with at least one copy of the following risk alleles: T of SNP ( $-590 \mathrm{C}>\mathrm{T} \mathrm{IL-4),} \mathrm{C} \mathrm{of} \mathrm{SNP} \mathrm{(-573G} \mathrm{>} \mathrm{C} \mathrm{IL-6),} \mathrm{A} \mathrm{of}$ SNP ( $-592 \mathrm{C}>\mathrm{A}$ IL-10), T of SNP (-819C > T IL-10) and T of SNP (-509C > T TGFB1), had an adjusted odds ratio (OR) of 2. 08 (95\% Cl 1.475-2.934, $p=0.0001)$, an OR of 1.70 (95\% Cl 1.208-2.404, $p=0.002)$, an OR of 1.87 (95 \% Cl 1.332-2. $630, p=0.0001$ ), an OR of 1.67 (95\% Cl 1.192-2.353, $p=0.003$ ) and an OR of 1.91 (95\% Cl 1.354-2.701, $p=0.0001$ ) , respectively, for CC. The burden of carrying two or more of these risk alleles was found to have an additive effect on the risk of CC ( $p$ trend $=0.0001)$. Finally, the serum levels of Th2 and Th3 cytokines were higher in CC cases than the controls; whereas IFNG levels, a Th1 cytokine, were higher in controls than CC cases.

Conclusion: The significant associations of five SNPs with CC indicate that these polymorphisms are potential candidates for predicting the risk of development of CC, representing a risk allelic load for CC and can be used as a biomarker of susceptibility to this disease.

Keywords: Genetic susceptibility profile, Cytokines, Promoter polymorphisms, Serum levels, Cervical neoplasm

\footnotetext{
* Correspondence: vmarina@insp.mx

'Dirección de Infecciones Crónicas y Cáncer. Centro de Investigación sobre Enfermedades Infecciosas, Instituto Nacional de Salud Pública (INSP), (Chronic Infectious Diseases and Cancer Division. Center for Research on Infectious Diseases. National Institute of Public Health Mexico), Av. Universidad 655, Santa María Ahuacatitlán, Cuernavaca C.P.62100, Morelos, Mexico

Full list of author information is available at the end of the article
} 


\section{Background}

Cervical cancer (CC) ranks third as a cause of death among women worldwide, with an estimated overall mortality rate of 15 per 100,000 women [1]. CC was the second most common cause of death in Mexican women in $2011(10.4 \%)$ [2]. The immune system plays key roles during HPV-associated carcinogenesis, as HPV clearance is determined by specific immunological reactions [3]. Thus, CC seems to be due in part to a failure of the immune system, which is unable to eliminate persistent HPV infections and virus-transformed cells [4].

A local predominance of $\mathrm{T}$ helper 2 (Th2) cytokine profile expression (IL-4, IL-6, IL-10) and an impaired cellular immune response induced by immune suppressor cytokines, such as IL-10 and Transforming Growth Factor Beta 1 (TGFB1) in association with a diminished Th1 profile, has been demonstrated in patients with CC $[5,6]$. Cytokines are key players in the immune system and several polymorphisms identified in their gene promoters may be responsible for variations in expression levels observed between individuals in different diseases [7].

Single nucleotide polymorphisms (SNPs) in IL-4, IL-6, IL-10, TGFB1, Tumor Necrosis Factor-alpha (TNF) and Interferon-gamma (IFNG) genes that cause variations in host immune response may contribute to $\mathrm{CC}$ risk. Since the boom of the genomic era, there are have been numerous reports of polymorphisms associated with $\mathrm{CC}$ risk; however, very few of the studied polymorphisms in this neoplasm have shown consistent associations across studies and populations. A large number of SNPs have been identified in IL-4, IL-6, IL-10, TGFB1, TNF e IFNG and many of them have been studied regarding their association with $\mathrm{CC}$ in different populations, particularly $-592 \mathrm{C}>\mathrm{A},-819 \mathrm{C}>\mathrm{T}$ and $-1082 \mathrm{~A}>\mathrm{G}$ of IL-10, $-509 \mathrm{C}>$ T TGFB1 and -308G $>$ A of TNF [8].

In this study, we analyzed the association between -59 0C > T (IL-4), -573G > C (IL-6), $-592 \mathrm{C}>\mathrm{A}$ (IL-10), -819 $\mathrm{C}>\mathrm{T}$ (IL-10), $-1082 \mathrm{~A}>\mathrm{G}$ (IL-10), $-509 \mathrm{C}>\mathrm{T}(\mathrm{TGFB} 1),-8$ 00G > A (TGFB1), $-308 \mathrm{G}>\mathrm{A}$ (TNF) and $-1615 \mathrm{C}>\mathrm{T}$ (IF NG) gene promoter polymorphisms and the risk for CC in Mexican women. These SNPs were selected based on two criteria: validated SNPs for frequency or for utilization in the HAPmap Project and SNPs in the promoter region with potential role in transcriptional regulation of each cytokine evaluated. Furthermore, we determined whether there are variations in serum protein levels of these cytokines according to diagnostic and allelic variation of each SNP.

\section{Methods}

\section{Study design and population}

A clinic-based case-control study matched by age ( \pm 5 years) $1: 1,(n=200$ per group) was conducted at the National Cancer Institute's (INCan) Gynecology Service in Mexico City between September 2010 and December 2011. Cases with cervical squamous cell carcinoma confirmed by two pathologists were included, and women with a negative Papanicolaou study and a normal colposcopy were selected as controls and matched to the cases by age ( \pm 5 years). All participants were HPV 16-positive, since this was an inclusion criterion. The analyzed population was Mexican mestizo with a history of three previous generations being born in Mexico and with a residency period of $>1$ year in the study area. To eliminate any selection bias, the authors screened CC cases and controls to ensure that they had never been diagnosed with chronic inflammatory diseases. The Bioethics and Research Committees at INCan (reference INCan/ $\mathrm{CC} / 326 / 10 \mathrm{CB} / 609)$ and at the Instituto Nacional de Salud Pública (INSP, reference CI814 and CI1289 No. 1624) approved the study, which was carried out according to the Helsinki Declaration. All participants signed an informed consent to participate in this study, agreeing also to the subsequent publication of the results. Each subject was interviewed regarding lifestyle and socio-demographic and hormonal factors known to be associated with an increased risk of CC.

\section{Specimen collection and sample processing}

Cervical epithelial cell scrapings from the controls and fresh cell biopsies from the women diagnosed with $\mathrm{CC}$ were used for this study. Peripheral blood mononuclear cells (PBMC) from all subjects were obtained by Ficollhypaque density gradients (Hystopaque, Sigma Chemical Co). Genomic DNA was extracted from PBMC using the Genomic DNA Purification Kit (Fermentas Life Sciences, Lithuania) and from cervical epithelial scrapings and biopsies previously digested with proteinase K. DNA concentration and purity were evaluated with a Thermo Scientific NanoDropTM 1000 Spectrophotometer (260/280) and the integrity of the DNA was determined by electrophoresis in agarose gels at $0.8 \%$.

Cervical epithelial scrapings and biopsy specimens were tested for HPV by PCR amplification, using consensus primers MY09/MY11, LIC1/LIC2, and GP5/GP6. GAPDH (250 bp) was used as an internal control for DNA quality; SiHa was used as a positive control, and deionized $\mathrm{H} 2 \mathrm{O}$ as a negative control. The purified DNA band was sequenced using the Sanger method. After analyzing the sequences by BLAST, only HPV 16positive women were included in this study. Serum protein levels of IL-4, IL-6, IL-10, TGFB1, TNF, and IFNG were determined using the Human high sensitivity ELISA kit (Abcam, Cambridge UK). All assays were done by duplicate and the final concentration (picograms per millilitre $[\mathrm{pg} / \mathrm{ml}]$ ) and TGFB1 (nanograms per millilitre $[\mathrm{ng} / \mathrm{ml}]$ ) of each cytokine corresponded to the average of the duplicate readings. 


\section{Genotyping}

The SNPs selection criteria were as follows: 1) Validated SNPs for frequency or for utilization in the HAPmap Project; 2) SNPs in the promoter region with potential role in the transcriptional regulation of each cytokine evaluated (the Ensemble program was used for this selection); 3) SNPs in IL-4, IL-6, IL-10, TGFB1, TNF and IFNG promoter, located in the binding sites of the transcription factors that potentially influence the transcriptional activity, reported in the following database: SNPper.URL: http//snpper.chip.org. Nine SNPs in the promoter region were genotyped using PCR with TaqMan fluorogenic probes in the ViiA ${ }^{\mathrm{ma}} 7$ (Applied Biosystems, Foster City, CA, USA), $(-590 \mathrm{C}>\mathrm{T}$ (IL-4) rs2243 250, -573G > C (IL-6) rs1800796, $-592 \mathrm{C}>\mathrm{A}(\mathrm{IL}-10)$ rs1 800872, $-819 \mathrm{C}>\mathrm{T}(\mathrm{IL}-10)$ rs1800871, $-1082 \mathrm{~A}>\mathrm{G}(\mathrm{IL}-10)$ rs1800896, $-509 \mathrm{C}>\mathrm{T}(\mathrm{TGFB} 1) \mathrm{rs} 1800469,-800 \mathrm{G}>\mathrm{A}$ (TG FB1) rs1800468, $-308 \mathrm{G}>\mathrm{A}$ (TNF) rs1800629 and -1615 $\mathrm{C}>\mathrm{T}$ (IFNG) rs2069705). All tests were performed in duplicate. The alleles were assigned using the $\mathrm{ViiA}^{\mathrm{ma}} 7$ software (Applied Biosystems). A call rate of 0.99 for controls and $\mathrm{CC}$ was used for quality control. When the call rate was less than 0.99, DNA was reextracted and a new genotyping was performed (only six samples required this procedure).

\section{Statistical analysis}

Reproductive factors and sexual lifestyle were evaluated by multinomial logistic regression models adjusted for age. The Hardy-Weinberg equilibrium for each SNP was assessed using the allelic frequencies of the control group. Genotype-specific and allele risks were estimated as odds ratios (OR) with associated $95 \%$ confidence intervals $(\mathrm{CI})$. All $p$-values were based on a two-sided hypothesis test using logistic regression analyses in the three inheritance models and adjusting by potential confounders (age, CC history and smoking history). The Bonferroni method was used to correct the multiple comparisons $(\alpha=0.05 / 9=0.0055)$. The effect of having one or more risk-associated alleles with $\mathrm{CC}$ was evaluated using multiple logistic regressions. All possible 2way interactions among SNPs and between SNPs and serum level of IL-4, IL-6, IL-10, TGFB1, TNF e IFNG were tested by multivariate logistic models. Tertiles for the serum levels of each cytokine according to the respective observed distribution in the HPV-positive control group were created to evaluate their association with CC by multinomial logistic regression models. The mean differences of the serum levels of cytokines between $\mathrm{CC}$ and controls stratified by genotypes were assessed by linear regression models adjusted by age, CC history and smoking history.

Stratification by ethnicity that could potentially confound genetic analyses was avoided by confining our analysis to the Mexican mestizo population with two previous generations born in Mexico. The power calculation for each of the analyzed SNPs was evaluated taking into account the value of $\mathrm{n}$ fixed for the study and the minor allele frequency for each SNP in the NCL (P1), with an expected OR of 1.2, 1.5, 2, 2.5 and 3. The established alpha value was 0.05 . The P2 calculation was performed using the following formula: P1*OR/(1-P1) + (P1*OR). The statistic power obtained in the regression analysis for each SNP was as follows: $-590 \mathrm{C}>\mathrm{T}$ of IL-4 (0.99); $-573 \mathrm{G}>\mathrm{C}$ of IL-6 (0.92); $-592 \mathrm{C}>\mathrm{A}(0.98),-819 \mathrm{C}>\mathrm{T}$ (0.91) and $-1082 \mathrm{~A}>\mathrm{G}(0.14)$ of IL-10; $-509 \mathrm{C}>\mathrm{T}$ of TGFB1 (0.98); $-308 \mathrm{G}>\mathrm{A}$ of TNF (0.28) and $-1615 \mathrm{C}>\mathrm{T}$ of IFNG (0.99). All the statistical analyses were performed in the STATA program, version 13.0 (StataCorp, Collage Station, TX, EUA).

\section{Results}

The analyses confirmed that known reproductive and sexual lifestyle risk factors for CC were statistically different between study groups. As expected, we found a significant positive association of CC diagnosis with age at first intercourse, parity, number of lifetime sexual partners, cancer family history and smoking history. The study did not find the history of previous Sexually Transmitted Diseases (STDs) and use of contraceptive methods to be risk factors for $\mathrm{CC}$ in this population (Table 1). Given the best score in the goodness of fit tests performed for all the logistic models evaluated, we carried out further multinomial logistic regression analysis, adjusting for cancer family history, smoking history and age. We observed no significant deviations from HWE among controls in any of the genotyped SNPs. The SNP -800G > A (TGFB1) rs1800468, was found not to be polymorphic with a minor allele frequency (MAF) of $<1 \%$ (Table 2 ).

We found a highly significant positive association with $\mathrm{CC}$ for minor allele homozygotes of $-590 \mathrm{C}>\mathrm{T}$ (IL-4), $-573 \mathrm{G}>\mathrm{C}$ (IL-6), $-592 \mathrm{C}>\mathrm{A}(\mathrm{IL}-10),-819 \mathrm{C}>\mathrm{T}(\mathrm{IL}-10)$ and $-509 \mathrm{C}>\mathrm{T}$ (TGFB1). Odds ratios and $\mathrm{p}$ trend were $\mathrm{OR}=4.36,95 \%$ CI $2.166-8.803(p=0.0001) ; \mathrm{OR}=3.2$, $95 \%$ CI $1.572-6.535(p=0.002) ; \mathrm{OR}=3.28,95 \% \mathrm{CI}$ $1.660-6.508 \quad(p=0.0001) ; \mathrm{OR}=2.695 \%$ CI 1.330 $5.116(p=0.004)$; and OR $=3.73,95 \%$ CI $1.842-7.572$ $(p=0.0001)$, respectively. For $-1615 \mathrm{C}>\mathrm{T} \quad$ (IFNG) minor allele homozygotes, we also found a significant negative association with $\mathrm{CC}(\mathrm{OR}=0.11,95 \% \mathrm{CI}$ (0.038-0.351)), accompanied with a significant negative trend $(p=0.0001)$.

In order to explore whether the evaluated SNPs could act together to increase CC risk, allele load was calculated (Table 3). We indeed found that having two or more risk alleles had a statistically significant association with $\mathrm{CC}$, compared with having no risk 
Table 1 Analysis of the reproductive and sexual life style conventional risk factors for cervical cancer in study population

\begin{tabular}{|c|c|c|c|}
\hline \multirow[t]{2}{*}{ Sociodemographic characteristics } & \multirow{2}{*}{$\begin{array}{l}n(\%) \text { Controls/n (\%) CC } \\
n=200 / 200\end{array}$} & \multicolumn{2}{|l|}{$\mathrm{OR}^{\mathrm{c}}(95 \% \mathrm{Cl})$} \\
\hline & & Cervical cancer (CC) & $p$ value \\
\hline \multicolumn{4}{|l|}{ Age of menarche (years) } \\
\hline$<12$ & $82(41) / 76(38)$ & 1 (reference) & \\
\hline$\geq 12$ & $118(56) / 124(62)$ & $0.76(0.47-1.22)$ & 0.26 \\
\hline \multicolumn{4}{|l|}{ Age at first intercourse (years) } \\
\hline$\geq 18$ & $114(57) / 50(25)$ & 1 (reference) & \\
\hline$<18$ & $86(43) / 150(75)$ & $5.64(3.32-9.56)^{b}$ & 0.0001 \\
\hline \multicolumn{4}{|l|}{ Parity } \\
\hline$\leq 3$ & $177(88.5) / 71(35.5)$ & 1 (reference) & \\
\hline$>3$ & $23(11.5) / 129(64.5)$ & $7.41(4.23-12.98)^{b}$ & 0.0001 \\
\hline \multicolumn{4}{|l|}{ Number of lifetime sexual partners } \\
\hline$<3$ & $169(84.5) / 148(74)$ & 1 (reference) & \\
\hline 4 a 9 & $28(14) / 50(25)$ & $2.27(1.24-4.15)^{b}$ & 0.008 \\
\hline$>10$ & $3(1.5) / 2(1)$ & $2.79(0.42-18.41)$ & 0.28 \\
\hline \multicolumn{4}{|l|}{ Contraceptive method } \\
\hline None & $28(14) / 111(55.5)$ & 1 (reference) & \\
\hline Non hormonals & $88(44) / 56(28)$ & $0.25(0.139-0.458)$ & 0.0001 \\
\hline Hormonal methods 6 months- 5 years & $84(42) / 33(16.5)$ & $0.15(0.08-0.29)^{b}$ & 0.0001 \\
\hline \multicolumn{4}{|l|}{ History of previous STD } \\
\hline None & $109(54.5) / 144(72)$ & 1 (reference) & \\
\hline Herpes & $5(2.5) / 2(1)$ & $0.4(0.065-2.44)$ & 0.32 \\
\hline Chlamydia & $1(0.5) / 1(0.5)$ & $0.46(0.028-7.50)$ & 0.58 \\
\hline Candidiasis & $33(16.5) / 1(0.5)$ & $0.02(0.003-0.235)$ & 0.001 \\
\hline Vaginosis & $33(16.5) / 49(24.5)$ & $1.32(0.73-2.39)$ & 0.34 \\
\hline HPV & $19(9.5) / 3(1.5)$ & $0.18(0.04-0.69)$ & 0.01 \\
\hline \multicolumn{4}{|l|}{ Cancer family history } \\
\hline No & $176(88) / 158(79)$ & 1 (reference) & \\
\hline Yes & $24(12) / 42(21)$ & $2.19(1.15-4.16)^{b}$ & 0.01 \\
\hline \multicolumn{4}{|l|}{ Smoking history } \\
\hline No & $155(77.5) / 125(62.5)$ & 1 & \\
\hline Yes & $45(22.5) / 75(37.5)$ & $2.15(1.28-3.63)^{b}$ & 0.004 \\
\hline
\end{tabular}

alleles, $p$ trend $=0.0001$. Levels in serum of IL-4, IL-6 and IL-10 were much higher in patients with CC than in HPV-positive control patients $(p=0.00001)$, (Fig. 1). In contrast, IFNG and TNF serum levels were lower than those observed in HPV-positive control patients $(p=0.00001)$, (Fig. 2). Serum levels of TGFB1 were significantly higher in comparison with the other cytokines and the difference between control and CC patients was statistically significant $(p<0.00001)$ (Fig. 3).
We stratified the SNPs of interest by polymorphism genotypes to explore whether they had a relationship with levels of serum cytokines seen in $\mathrm{CC}$ patients. Only polymorphisms $-592 \mathrm{C}>\mathrm{A}$ and $-819 \mathrm{C}>\mathrm{T}$ of $\mathrm{IL}-10,-308 \mathrm{G}>\mathrm{A}$ (TNF) and -509C $>$ T (TGFB1) showed statistically significant differences in serum cytokines levels between minor allele homozygous and ancestral allele homozygous in CC patients (Table 4). When we evaluated the interaction between each of the SNPs: $-590 \mathrm{C}>\mathrm{T}$ (IL-4), $-573 \mathrm{G}>\mathrm{C}$ (IL-6), $-592 \mathrm{C}>\mathrm{A}, \quad-819 \mathrm{C}>\mathrm{T}$ and $-1082 \mathrm{~A}>\mathrm{G}$ (IL-10), 
Table 2 Association analysis of SNP in promoter of IL-4, IL-6, IL-10, TGF $3-1$, TNF-a, IFN- $\gamma$ with CC

\begin{tabular}{|c|c|c|c|}
\hline Polymorphism & $n(\%) C C /(\%)$ controls $(n=200 / 200)$ & $\mathrm{OR}^{\mathrm{c}}(95 \% \mathrm{Cl})$ & $p$ Value* $^{*}$ \\
\hline \multicolumn{4}{|c|}{ IL-4 -590C > T (rs2243250) } \\
\hline \multicolumn{4}{|c|}{ Codominant model } \\
\hline $\mathrm{C} / \mathrm{C}$ & $32(16) / 60(30)$ & 1 & \\
\hline$C / T$ & $87(43.5) / 102(51)$ & $1.50(0.804-2.807)$ & 0.2 \\
\hline $\mathrm{T} / \mathrm{T}$ & $81(40.5) / 38(19)$ & $4.36(2.166-8.803)^{\mathrm{b}}$ & 0.0001 \\
\hline \multicolumn{4}{|c|}{ Dominant model } \\
\hline $\mathrm{C} / \mathrm{C}$ & $32(16) / 60(30)$ & 1 & \\
\hline $\mathrm{C} / \mathrm{T}+\mathrm{T} / \mathrm{T}$ & $168(84) / 140(70)$ & $2.22(1.238-3.987)$ & 0.007 \\
\hline \multicolumn{4}{|c|}{ Recessive model } \\
\hline $\mathrm{C} / \mathrm{C}+\mathrm{C} / \mathrm{T}$ & $119(59.5) / 162(81)$ & 1 & \\
\hline $\mathrm{T} / \mathrm{T}$ & $81(40.5) / 38(19)$ & 3.3 (1.909-5.707) & 0.0001 \\
\hline \multicolumn{4}{|l|}{ Alleles } \\
\hline C & $151(37.7) / 222(56)$ & 1 & \\
\hline $\mathrm{T}$ & $249(62.25) / 178(44)$ & 2.08 (1.475-2.934) & 0.0001 \\
\hline$p H W E^{a}$ & & & 0.6 \\
\hline \multicolumn{4}{|c|}{ IL-6 -573G > C (rs1800796) } \\
\hline \multicolumn{4}{|c|}{ Codominant model } \\
\hline $\mathrm{G} / \mathrm{G}$ & $54(27) / 89(44.5)$ & 1 & \\
\hline $\mathrm{G} / \mathrm{C}$ & $85(42.5) / 91(45.5)$ & $1.47(0.875-2.499)$ & 0.14 \\
\hline $\mathrm{C} / \mathrm{C}$ & $61(30.5) / 20(10)$ & $3.2(1.572-6.535)^{b}$ & 0.001 \\
\hline \multicolumn{4}{|c|}{ Dominant model } \\
\hline $\mathrm{G} / \mathrm{G}$ & $54(27) / 89(44.5)$ & 1 & \\
\hline $\mathrm{G} / \mathrm{C}+\mathrm{C} / \mathrm{C}$ & $146(73) / 111(55.5)$ & $1.82(1.111-2.983)$ & 0.017 \\
\hline \multicolumn{4}{|c|}{ Recessive model } \\
\hline $\mathrm{G} / \mathrm{G}+\mathrm{G} / \mathrm{C}$ & $139(69.5) / 180(90)$ & 1 & \\
\hline $\mathrm{C} / \mathrm{C}$ & $61(30.5) / 20(10)$ & $2.58(1.348-4.934)$ & 0.004 \\
\hline \multicolumn{4}{|l|}{ Alleles } \\
\hline C & $193(48.25) / 269(67.25)$ & 1 & \\
\hline $\mathrm{T}$ & $207(51.75) / 131$ (32.75) & $1.70(1.208-2.404)$ & 0.002 \\
\hline p HWE & & & 0.72 \\
\hline \multicolumn{4}{|c|}{ IL-10 -592C > A (rs1800872) } \\
\hline \multicolumn{4}{|c|}{ Codominant model } \\
\hline $\mathrm{C} / \mathrm{C}$ & $44(22) / 85(42.5)$ & 1 & \\
\hline C/A & $98(49) / 85(42.5)$ & $2.08(1.190-3.656)$ & 0.01 \\
\hline $\mathrm{A} / \mathrm{A}$ & $58(29) / 30(15)$ & $3.28(1.660-6.508)^{b}$ & 0.001 \\
\hline \multicolumn{4}{|c|}{ Dominant model } \\
\hline $\mathrm{C} / \mathrm{C}$ & $44(22) / 85(42.5)$ & 1 & \\
\hline$C / A+A / A$ & $156(78) / 115$ (57.5) & $2.40(1.416-4.072)$ & 0.001 \\
\hline \multicolumn{4}{|c|}{ Recessive model } \\
\hline$C / C+C / A$ & $142(71) / 170(85)$ & 1 & \\
\hline A/A & $58(29) / 30(15)$ & $2.09(1.166-3.756)$ & 0.013 \\
\hline \multicolumn{4}{|l|}{ Alleles } \\
\hline C & $185(46.37) / 255(63.75)$ & 1 & \\
\hline
\end{tabular}


Table 2 Association analysis of SNP in promoter of IL-4, IL-6, IL-10, TGFß-1, TNF-a, IFN- $\gamma$ with CC (Continued)

\begin{tabular}{|c|c|c|c|}
\hline A & $214(53.63) / 145(36.25)$ & $1.87(1.332-2.630)$ & 0.0001 \\
\hline p HWE ${ }^{a}$ & & & 0.25 \\
\hline \multicolumn{4}{|c|}{ IL-10 -819C > T (rs 1800871) } \\
\hline \multicolumn{4}{|c|}{ Codominant model } \\
\hline $\mathrm{C} / \mathrm{C}$ & $49(24.5) / 81(40.5)$ & 1 & \\
\hline $\mathrm{C} / \mathrm{T}$ & $97(48.5) / 85(42.5)$ & $1.88(1.078-3.281)$ & 0.02 \\
\hline $\mathrm{T} / \mathrm{T}$ & $54(27) / 34(17)$ & $2.6(1.330-5.116)^{b}$ & 0.005 \\
\hline \multicolumn{4}{|c|}{ Dominant model } \\
\hline $\mathrm{C} / \mathrm{C}$ & $49(24.5) / 81(40.5)$ & 1 & \\
\hline $\mathrm{C} / \mathrm{T}+\mathrm{T} / \mathrm{T}$ & $151(75.5) / 119(59.5)$ & $2.08(1.237-3.514)$ & 0.006 \\
\hline \multicolumn{4}{|c|}{ Recessive model } \\
\hline $\mathrm{C} / \mathrm{C}+\mathrm{C} / \mathrm{T}$ & $146(73) / 166(83)$ & 1 & \\
\hline $\mathrm{T} / \mathrm{T}$ & $54(27) / 34(17)$ & $1.77(0.997-3.174)$ & 0.05 \\
\hline \multicolumn{4}{|l|}{ Alleles } \\
\hline C & $195(48.75) / 247(61.75)$ & 1 & \\
\hline $\mathrm{T}$ & $205(51.25) / 153(38.25)$ & $1.67(1.192-2.353)$ & 0.003 \\
\hline p HWE ${ }^{a}$ & & & 0.15 \\
\hline \multicolumn{4}{|c|}{ IL-10 -1082A > G (rs1800896) } \\
\hline \multicolumn{4}{|c|}{ Codominant model } \\
\hline $\mathrm{A} / \mathrm{A}$ & $121(60.5) / 110(55)$ & 1 & \\
\hline$A / G$ & 70 (35)/78 (39) & $0.73(0.447-1.205)$ & 0.22 \\
\hline $\mathrm{G} / \mathrm{G}$ & $9(4.5) / 12(6)$ & $0.89(0.298-2.659)$ & 0.83 \\
\hline \multicolumn{4}{|c|}{ Dominant model } \\
\hline $\mathrm{A} / \mathrm{A}$ & $121(60.5) / 110(55)$ & 1 & \\
\hline $\mathrm{A} / \mathrm{G}+\mathrm{G} / \mathrm{G}$ & 79 (39.5)/90 (45) & $0.75(0.466-1.210)$ & 0.24 \\
\hline \multicolumn{4}{|c|}{ Recessive model } \\
\hline $\mathrm{A} / \mathrm{A}+\mathrm{A} / \mathrm{G}$ & $191(95.5) / 188$ (94) & 1 & \\
\hline $\mathrm{G} / \mathrm{G}$ & $9(4.5) / 12(6)$ & $1.004(0.342-2.944)$ & 0.99 \\
\hline \multicolumn{4}{|l|}{ Alleles } \\
\hline A & $312(78) / 298(74.5)$ & 1 & \\
\hline G & $88(22) / 102(25.5)$ & $0.83(0.561-1.234)$ & 0.36 \\
\hline p HWE ${ }^{a}$ & & & 0.7 \\
\hline \multicolumn{4}{|c|}{ TGFB1 -509C > T (rs1800469) } \\
\hline \multicolumn{4}{|c|}{ Codominant model } \\
\hline $\mathrm{C} / \mathrm{C}$ & $61(30.5) / 80(40)$ & 1 & \\
\hline $\mathrm{C} / \mathrm{T}$ & $87(43.5) / 96(48)$ & $1.46(0.854-2.514)$ & 0.16 \\
\hline $\mathrm{T} / \mathrm{T}$ & $52(26) / 24(12)$ & $3.73(1.842-7.572)^{b}$ & 0.0001 \\
\hline \multicolumn{4}{|c|}{ Dominant model } \\
\hline $\mathrm{C} / \mathrm{C}$ & $61(30.5) / 80(40)$ & 1 & \\
\hline $\mathrm{C} / \mathrm{T}+\mathrm{T} / \mathrm{T}$ & $139(69.5) / 120(60)$ & $1.91(1.151-3.174)$ & 0.01 \\
\hline \multicolumn{4}{|c|}{ Recessive model } \\
\hline $\mathrm{C} / \mathrm{C}+\mathrm{C} / \mathrm{T}$ & $148(74) / 176(88)$ & 1 & \\
\hline $\mathrm{T} / \mathrm{T}$ & $52(26) / 24(12)$ & $2.98(1.593-5.597)$ & 0.001 \\
\hline \multicolumn{4}{|l|}{ Alleles } \\
\hline C & $209(52.25) / 256(64)$ & 1 & \\
\hline
\end{tabular}


Table 2 Association analysis of SNP in promoter of IL-4, IL-6, IL-10, TGF $\beta-1$, TNF-a, IFN- $\gamma$ with CC (Continued)

\begin{tabular}{|c|c|c|c|}
\hline $\mathrm{T}$ & $191(47.75) / 144(36)$ & $1.91(1.354-2.701)$ & 0.0001 \\
\hline \multicolumn{3}{|l|}{ p HWE ${ }^{a}$} & 0.55 \\
\hline \multicolumn{4}{|c|}{ TNFa -308G > A (rs 1800629) } \\
\hline \multicolumn{4}{|c|}{ Codominant model } \\
\hline $\mathrm{G} / \mathrm{G}$ & $164(82) / 161(80.5)$ & 1 & \\
\hline $\mathrm{G} / \mathrm{A}$ & $26(13) / 36(18)$ & $0.55(0.281-1.081)$ & 0.08 \\
\hline $\mathrm{A} / \mathrm{A}$ & $10(5) / 3(1.5)$ & $1.52(0.305-7.631)$ & 0.6 \\
\hline \multicolumn{4}{|c|}{ Dominant model } \\
\hline $\mathrm{G} / \mathrm{G}$ & $164(82) / 161(80.5)$ & 1 & \\
\hline $\mathrm{G} / \mathrm{A}+\mathrm{A} / \mathrm{A}$ & $36(18) / 39(19.5)$ & $0.62(0.332-1.187)$ & 0.15 \\
\hline \multicolumn{4}{|c|}{ Recessive model } \\
\hline $\mathrm{G} / \mathrm{G}+\mathrm{G} / \mathrm{A}$ & $190(95) / 197(98.5)$ & 1 & \\
\hline $\mathrm{A} / \mathrm{A}$ & $10(5) / 3(1.5)$ & $1.74(0.356-8.519)$ & 0.49 \\
\hline \multicolumn{4}{|l|}{ Alleles } \\
\hline G & $354(88.5) / 358(89.5)$ & 1 & \\
\hline A & $46(11.50) / 42(10.5)$ & $0.74(0.421-1.305)$ & 0.3 \\
\hline$p H W E^{a}$ & & & 0.54 \\
\hline \multicolumn{4}{|c|}{ IFN- $-\gamma-1615 C>$ T (rs2069705) } \\
\hline \multicolumn{4}{|c|}{ Codominant model } \\
\hline $\mathrm{C} / \mathrm{C}$ & $143(71.5) / 88(44)$ & 1 & \\
\hline$C / T$ & $51(25.1) / 91(45.5)$ & $0.25(0.149-0.445)$ & 0.0001 \\
\hline$T / T$ & $6(3) / 21(10.5)$ & $0.11(0.038-0.351)^{\mathrm{b}}$ & 0.0001 \\
\hline \multicolumn{4}{|c|}{ Dominant model } \\
\hline $\mathrm{C} / \mathrm{C}$ & $143(71.5) / 88(44)$ & 1 & \\
\hline$C / T+T / T$ & $57(28.5) / 112(56)$ & $0.22(0.135-0.385)$ & 0.0001 \\
\hline \multicolumn{4}{|c|}{ Recessive model } \\
\hline $\mathrm{C} / \mathrm{C}+\mathrm{C} / \mathrm{T}$ & $194(97) / 179(89.5)$ & 1 & \\
\hline$T / T$ & $6(3) / 21(10.5)$ & $0.19(0.068-0.581)$ & 0.003 \\
\hline \multicolumn{4}{|l|}{ Alleles } \\
\hline C & $337(84.25) / 267(66.75)$ & 1 & \\
\hline T & $63(15.75) / 133(33.25)$ & $0.30(0.203-0.468)$ & 0.0001 \\
\hline$p H W E^{a}$ & & & 0.72 \\
\hline \multicolumn{4}{|c|}{$\begin{array}{l}\text { Bold text denotes significant } p \text { values }(p<0.006) \\
{ }^{*} p<=0.006 \text { Multiples comparisons adjustment by Bonferroni m } \\
\text { a Hardy-Weinberg Equilibrium in controls } \\
\text { b Statistically significant } p \text { value for trend ( } p<0.001) \\
\text { cOdds Ratio adjusted by age, CC history and smoking history }\end{array}$} \\
\hline \multicolumn{2}{|c|}{$\begin{array}{l}-509 \mathrm{C}>\mathrm{T} \quad(\mathrm{TGFB} 1),-308 \mathrm{G}>\mathrm{A}(\mathrm{TNF}) \text { and }-1615 \mathrm{C}>\mathrm{T} \\
\text { (IFNG) and respective serum levels, as well as the SNP-SNP } \\
\text { interaction, no statistically significant interaction on CC was } \\
\text { found (data not shown). }\end{array}$} & \multirow{2}{*}{\multicolumn{2}{|c|}{$\begin{array}{l}\text { polymorphisms on CC have been reported in different } \\
\text { populations, our results show for the first time a risk } \\
\text { allelic load in Th2 and Th3 cytokines genes as a bio- } \\
\text { marker of susceptibility to CC. } \\
\text { HR-HPV persistent infection is a necessary but not } \\
\text { sufficient cause for CC [9]; a combination of several risk } \\
\text { factors is required for the disease to develop. The associ- } \\
\text { ation found in this study for the variables early-age of } \\
\text { first sexual intercourse, high number of sexual partners } \\
\text { and multiparity, confirms the known association reported } \\
\text { in previous epidemiological studies [10]. }\end{array}$}} \\
\hline \multicolumn{2}{|c|}{$\begin{array}{l}\text { The main findings of this study were a significant } \\
\text { positive association between CC with the SNP's: } \\
-590 \mathrm{C}>\mathrm{T} \text { (IL-4), }-573 \mathrm{G}>\mathrm{C} \text { (IL-6), }-592 \mathrm{C}>\mathrm{A} \text { (IL10), } \\
-819 \mathrm{C}>\mathrm{T} \text { (IL10) and }-509 \mathrm{C}>\mathrm{T} \text { (TGFB1) and their } \\
\text { serum levels. Although the effect of cytokine gene }\end{array}$} & & \\
\hline
\end{tabular}


Table 3 Risk allele load and risk for cervical cancer

\begin{tabular}{|c|c|c|c|c|c|c|}
\hline \multicolumn{7}{|c|}{ SNP's -590 (IL-4)/-573 (IL-6)/-592 (IL-10)/-819 (IL-10)/-509 (TGFB1) } \\
\hline \multirow{2}{*}{$\begin{array}{l}\text { Number of alleles } \\
\text { associated with CC }\end{array}$} & \multicolumn{3}{|l|}{$n$} & \multirow[t]{2}{*}{$\mathrm{OR}^{\mathrm{a}}$} & \multirow[t]{2}{*}{$\mathrm{Cl} 95 \%$} & \multirow[t]{2}{*}{$P$ value } \\
\hline & $\overline{\text { Total }}$ & CC & $\overline{\text { Controls }}$ & & & \\
\hline 0 & 312 & 119 & 193 & 1 & - & \\
\hline 1 & 116 & 60 & 56 & 1.4 & $0.832-2.386$ & 0.2 \\
\hline 2 & 133 & 69 & 64 & 1.75 & $1.072-2.881$ & 0.02 \\
\hline 3 & 137 & 85 & 52 & 2.54 & $1.563-4.159$ & 0.0001 \\
\hline$\geq 4$ & 99 & 66 & 33 & 2.86 & $1.608-5.098$ & 0.0001 \\
\hline$P$ trend & & & & & & 0.0001 \\
\hline
\end{tabular}

$n=$ Number of alleles

${ }^{a}$ Odds Ratio adjusted by age, $\mathrm{CC}$ history and smoking history

Bold text denotes significant $p$ values $(p<0.05)$

Trend $p$ value adjusted by age, $\mathrm{CC}$ history and smoking history

Genetic predisposing factors may influence the likelihood of, sensitivity to or persistence of HPV infection, as well as the rate of tumor development [11]. Various immune-suppressive states associated with a reduction in cellular immune responses are associated with increasingly severe cervical dysplasia and increased viral shedding, suggesting that a T-helper bias that opposes Th1 responses (ie, Th2 bias) might predispose to chronic infection [12-15].

To our knowledge, this is the first study to show that the IL-4 SNP rs2243250 is significantly associated with the risk of CC. IL-4 is an anti-inflammatory cytokine and the $\mathrm{T}$ allele of the SNP $-590 \mathrm{C}>\mathrm{T}$ has been associated with increased transcriptional activity in vitro [16]. The exact mechanism for this increment is not known.
However, since the SNP is located within 5'UTR of the gene, it may be possible that alterations in this gen could be influencing in its transcription and/or mRNA stabilization [17]. The IL-4 -590 SNP is a transition $(\mathrm{C} \rightarrow \mathrm{T})$ that has been associated with oral cancer and is a suitable genetic marker for screening for this condition [17]. Increased plasma concentrations of IL-4 can influence the immune status of an affected individual through several mechanisms and result in many phenotypes beyond the scope of the immune system [18].

Likewise, our results showed that the genotype $\mathrm{C} / \mathrm{C}$ of the IL-6 SNP -573G > C (rs1800796, previously denoted as $-572 \mathrm{G}>\mathrm{C}$ ), was significantly associated with the risk of $C C$ when compared with the heterozygous genotype GC. The IL-6 -573 SNP is a transversion $(G \rightarrow C)$ that was reported as a genetic risk factor of lung cancer risk in Singaporean Chinese non-smoking females [19]. IL-6 is a multifunctional cytokine that can regulate immune and inflammatory responses. In CC patients, high expression of IL- 6 correlate with a promoting effect in tumor cell growth by autocrine and/ or paracrine processes [20]. Accumulated data of overexpression of IL-6 mRNA and protein in CC cells have showed that the IL- 6 protein played important roles in CC development [12, 21, 22]. High levels of IL-6 are associated with the severity of disease and may promote tumor angiogenesis and cancer, which could be genetically determined at an individual level [23]. Clinical studies in CC patients report that elevated IL6 serum levels are associated with poor prognosis [24]. Variations in the IL- 6 gene have been found to be associated with the plasma levels of the protein [20] and

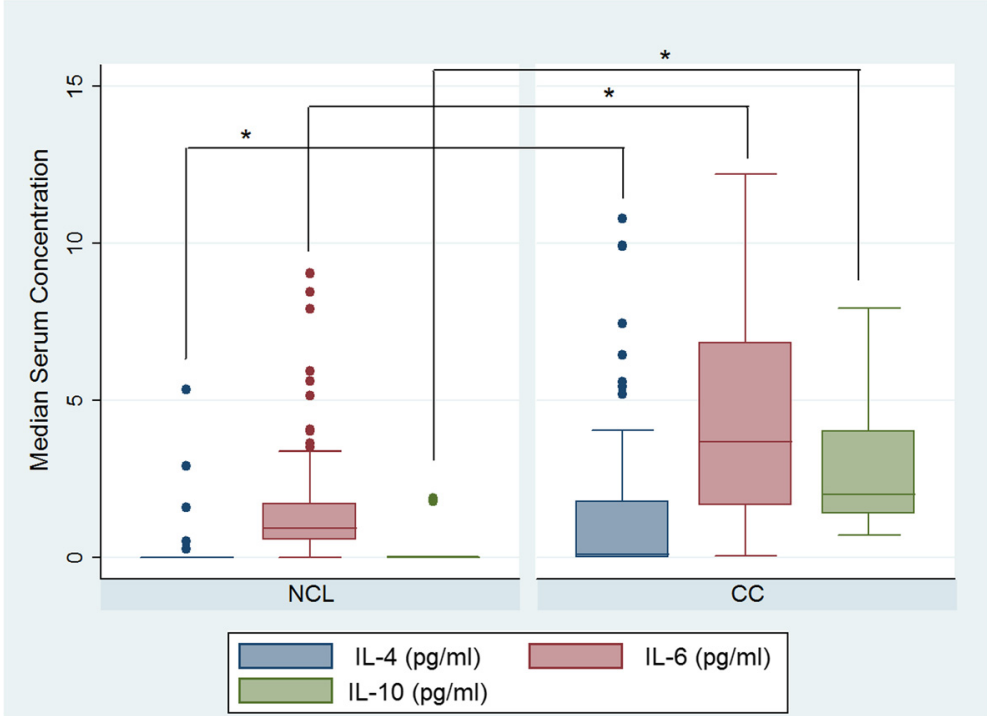

Fig. 1 Levels of serum Th2 cytokines in patients with cervical cancer (CC) and controls (NCL). Median serum concentration of IL-4 (pg/ml), $\mathrm{IL}-6(\mathrm{pg} / \mathrm{ml})$ and IL-10 $(\mathrm{pg} / \mathrm{ml})$. The asterisk represent a statistically significant $p$ value for Mann-Whitney test adjusted by multiple comparisons $(p=0.00001)$ 


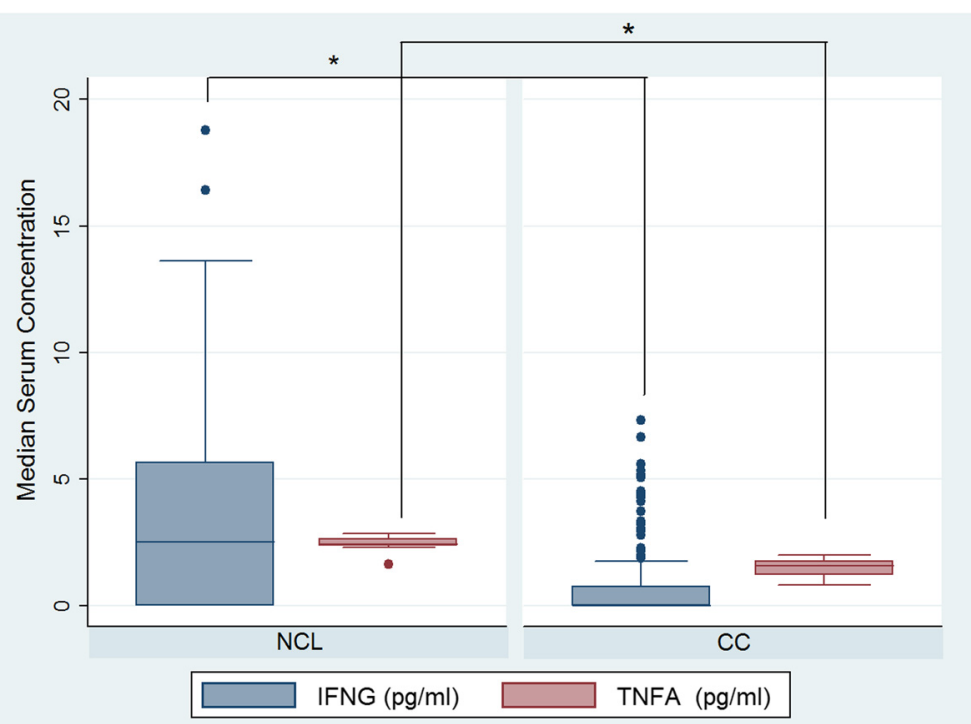

Fig. 2 Levels of serum Th1 cytokines in patients with cervical cancer (CC) and controls (NCL). Median serum concentration of IFNG (pg/ml) and TNF (pg/ml). The asterisk represent a statistically significant $p$ value for Mann-Whitney test adjusted by multiple comparisons $(p=0.00001)$

functional relevance has been ascribed to several IL-6 variants located in the promoter region, including $-573 \mathrm{G}>\mathrm{C}[25]$. However, in this study the concentrations of angiogenic cytokines, such as IL-6, do not vary with genotype. This result is similar to other study which explored whether polymorphisms in angiogenic cytokine genes may affect the levels of cytokines and which reported no variation [26].

With respect to IL-10 cytokine gene polymorphisms it has been reported that several important polymorphic sites in the IL-10 gene, including three in the promoter region $(-1082 \mathrm{~A}>\mathrm{G},-819 \mathrm{C}>\mathrm{T},-592 \mathrm{C}>\mathrm{A})$ may influence the transcription of IL-10 messenger RNA and the expression of IL-10 in vitro [27]. Several studies have investigated the possible role of IL-10 cytokine gene polymorphisms in CC [28]. The current study has shown that individuals homozygous for the A-allele of the -592 SNP are at three time's greater odds of having CC as compared to controls. The -592 SNP rs1800872 is a transversion $(\mathrm{C} \rightarrow \mathrm{A})$ that is located in the IL-10 promoter in a region with negative enhancer activity and is associated with loss of this activity [29], between putative consensus binding sequences for $\mathrm{Sp} 1$ and a sequence with similarity to that recognized by members of

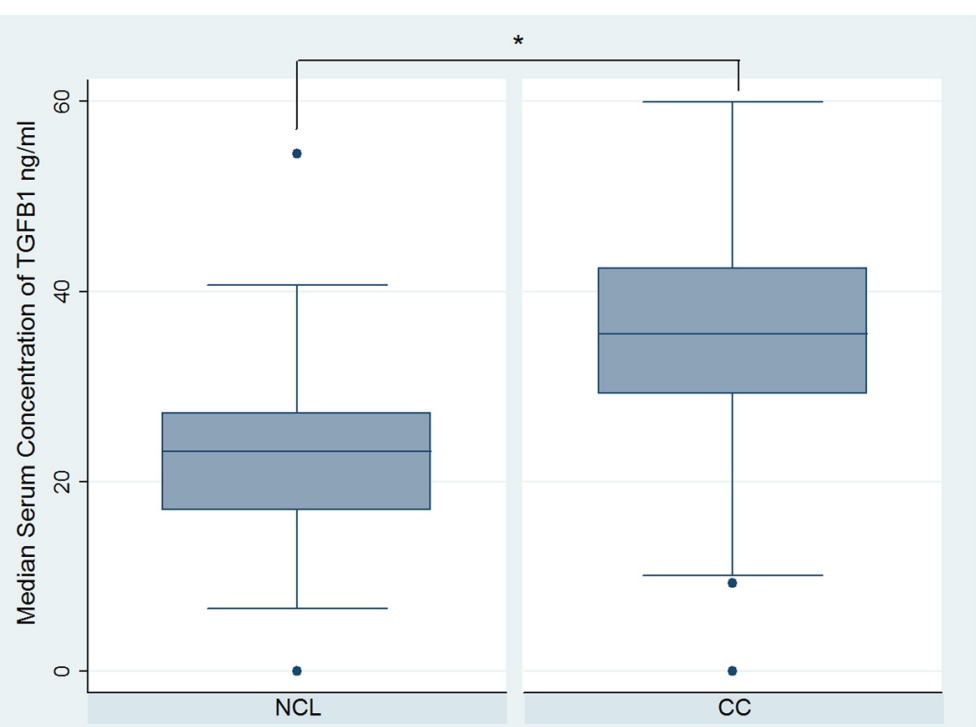

Fig. 3 Levels of serum Th3 cytokines in patients with cervical cancer (CC) and controls (NCL). Median serum concentration of TGFB1 (ng/ml). The asterisk represent a statistically significant $p$ value for Mann-Whitney test adjusted by multiple comparisons $(p<0.00001)$ 
Table 4 Estimated mean difference of cytokines serum levels between CC cases and controls stratified by genotypes

\begin{tabular}{|c|c|c|c|c|c|}
\hline \multirow[t]{2}{*}{ Diagnosis } & \multicolumn{5}{|l|}{$\beta^{\text {a }}$ coefficient $(95 \% \mathrm{Cl})$} \\
\hline & Polymorphism & Total without stratification & Ancestral allele homozygote & Heterozygote & Minor allele homozygote \\
\hline & IL-4 -590C > T (rs2243250) & & CC & $\mathrm{CT}$ & $\pi$ \\
\hline $\mathrm{NCL}$ & & - & - & - & - \\
\hline CC & & $1.0(0.696,1.307)$ & $0.61(0.269,0.970)$ & $1.22(0.713,1.736)$ & $0.87(0.214,1.539)$ \\
\hline & IL-6 -573G > C (rs1800796) & & GG & GC & $\mathrm{CC}$ \\
\hline $\mathrm{NCL}$ & & - & - & - & - \\
\hline CC & & $2.63(2.063,3.199)$ & $3.12(2.261,3.994)$ & $2.39(1.567,3.230)$ & $2.20(0.367,4.042)$ \\
\hline & IL-10 -592C > A (rs1800872) & & $\mathrm{CC}$ & CA & $\mathrm{AA}$ \\
\hline $\mathrm{NCL}$ & & - & - & - & - \\
\hline CC & & $2.55(2.255,2.859)$ & $2.27(1.805,2.737)$ & $2.55(2.063,3.04)$ & $2.62(1.911,3.333)$ \\
\hline & IL-10 -819C > T (rs1800871) & & CC & $C T$ & $\pi$ \\
\hline $\mathrm{NCL}$ & & - & - & - & - \\
\hline CC & & $2.55(2.255,2.859)$ & $2.24(1.760,2.722)$ & $2.45(1.980,2.927)$ & $2.83(2.111,3.555)$ \\
\hline & IL-10 -1082A > G (rs1800896) & & AA & $A G$ & GG \\
\hline $\mathrm{NCL}$ & & - & - & - & - \\
\hline CC & & $2.55(2.255,2.859)$ & $2.48(2.078,2.898)$ & $2.77(2.261,3.291)$ & $1.13(0.508,1.758)$ \\
\hline & IFN- $\gamma-1615 C>$ T (rs2069705) & & CC & $C T$ & $\pi$ \\
\hline $\mathrm{NCL}$ & & - & - & - & - \\
\hline CC & & $-2.58(-3.286,-1.891)$ & $-2.80(-3.687,-1.927)$ & $-2.61(-3.929,-1-291)$ & $-1.7(-6.097,2.685)$ \\
\hline & TNF-a -308G > A (rs 1800629) & & GG & GA & AA \\
\hline $\mathrm{NCL}$ & & - & - & - & - \\
\hline CC & & $-0.94(-1.026,-0.860)$ & $-0.91(-1.003,-0.816)$ & $-1.08(-1.30,-0.876)$ & $-1.33(-1.85,-0.813)$ \\
\hline & TGFB1 -509C > T (rs1800469) & & CC & $C T$ & $\pi$ \\
\hline $\mathrm{NCL}$ & & - & - & - & - \\
\hline $\mathrm{CC}$ & & $13.4(11.52,15.47)$ & $19.5(15.85,23.17)$ & $11.2(8.686,13.71)$ & $8.7(2.54,14.98)$ \\
\hline
\end{tabular}

Bold text denotes significant $p$ values $(p<0.05)$

${ }^{a}$ Adjusted by age, CC history and smoking history

Levels of serum cytokines are expressed in $\mathrm{pg} / \mathrm{ml}$ except TGFB1 $(\mathrm{ng} / \mathrm{ml})$

the ETS family proteins. Steinke et al., have demonstrated that the $\mathrm{C}$ to $\mathrm{A}$ nucleotide exchange results in increased IL-10 gene promoter activity and that the C variant of this SNP is a repressor element [29]. A previous study carried out in $695 \mathrm{CC}$ patients, 115 family-based patients and 586 unrelated controls, in Caucasian population, revealed an increased risk CC for individuals heterozygous for the A-allele of this SNP [30]. Like our study, two recent meta-analyses reported this SNP as a risk factor for developing CC, especially for Asians [28, 31].

Only one other study has investigated the IL-10 SNP $-819 \mathrm{C}>\mathrm{T}$ rs1800871 and CC. In this study the CT + TT genotype combination and $\mathrm{T}$ allele, was slightly higher in $150 \mathrm{CC}$ cases as compared with 162 age- and ethnicallymatched cervical cytology negative healthy controls. However, contrary to our investigation, the study did not show statistical significance [32]. At this time, a series of seven molecular epidemiological studies and meta- analyses have investigated the association between the IL-10 -819 SNP, a transition $(\mathrm{C} \rightarrow \mathrm{T})$ and the susceptibility to different cancer types among different populations [33]. Nevertheless, the results from these studies are inconsistent. Most studies investigating this SNP have focused on gastric cancer and some have found a reduced risk of gastric cancer among Asians but not among Caucasians [34]. The mechanism of the influence of IL10-819 SNP on carcinogenesis is still unknown [33].

The IL-10 -1082 SNP rs1800896 is a transition $(A \rightarrow G)$ and is the most extensively studied polymorphism in the IL-10 gene in cancer susceptibility [35]. Studies link this SNP to high/low IL-10 producer status. Functional analyses have shown that the -1082 region contains a putative ETS-like transcription factor-binding site and that nuclear factors from a monocyte cell line bind to this region. Transient transfection studies in an Epstein-Barr virus-transformed B cell line indicated that the $-1082 \mathrm{~A}$ allele confers a two fold increase in transcriptional activity 
of the IL-10 promoter compared to the G allele [36]. This polymorphism has been associated with $\mathrm{CC}$ risk in populations from Zimbabwe and Japan [30, 37], while studies in The Netherlands, South Africa, Hungary and China, similarly to our study did not find any association [35]. In the Japanese population, IL-10 -1082 genotypes corresponding to high production of interleukin (GA and GG) were significantly associated with CC severity [37]. The discrepancy of reported results among studies may be explained by the frequency of the G allele in healthy controls $[30,35,37]$. A previously meta-analyses reported in the subgroup analysis by ethnicity of the association of IL$10-1082 \mathrm{~A}$ allele with decreased CC susceptibility among whites only (A vs G: OR, 0.39; $95 \%$ CI, 0.32-0.47) [28]. As expected, the $\mathrm{G}$ allele frequency obtained in this study (0.25) was similar to that reported for Italy (0.37) [38] and Argentina (0.32) [39], showing no relation with CC risk.

On the other hand, the common TGFB1 promoter SNP -509 C-T (rs1800469) was associated with CC in our study, for all models of inheritance and analysis alleles. This SNP is a transition $(\mathrm{C} \rightarrow \mathrm{T})$ linked to a nearly twofold difference in plasma levels among individuals and with risk, progression, and outcome of numerous diseases [40]. This association with the pathogenesis of certain TGFB1related diseases can be due to transcriptional suppression by AP1 binding to $-509 \mathrm{C}$ [40].

Only one other study has investigated the SNP -509C > $\mathrm{T}$ rs1800469 and CC. In this study $150 \mathrm{CC}$ patients with -509TT had marginal low risk for stage I ( $p=0.04$, OR $=$ $0.95,95 \% \mathrm{CI}=0.91-0.99$ ). However, $-509 \mathrm{TT}$ genotype of TGFB1 was associated with increased risk of stage II of cancer $(p=0.07, \mathrm{OR}=3.13,95 \% \mathrm{CI}=0.87-11.14)$. In gene-environment interaction, carriers of TGFB1 -509TT genotype with tobacco usage were at higher risk of CC $(\mathrm{OR}=3.67,95 \% \mathrm{CI}=0.38-35.1)$ [41]. The association found in this study is according to previous report where TGF-beta family members play a key role in cellular growth, proliferation, differentiation and angiogenesis of several cancer types [42] and a marginal protection for early stage 1B but risk for stage II of CC of TGFB1 -509 T allele has been reported [41].

Our results indicated that TNF -308 SNP rs1800629, a transition $(\mathrm{G} \rightarrow \mathrm{A})$, had no effect on $\mathrm{CC}$ risk in the overall analysis. This polymorphism is the most studied polymorphism in terms of association with $\mathrm{CC}$ and severity with conflicting results. Four recent meta-analysis, pooled data from eight, twelve, fifteen and eighteen case-control studies respectively, have suggested that TNF-308G > A polymorphism is associated with an increased risk of CC [43-46]. The analysis stratified by ethnicity, showed that there was a significant association of this polymorphism and increased risk of CC in Asians [47] and in Caucasian and African populations [45]. In our study, the lack of association between TNF $-308 \mathrm{G}>\mathrm{A}$ polymorphism and $\mathrm{CC}$ was consistent with previous reports from African [48, 49] and Caucasian ethnicity $[39,50,51]$. Differences in ethnic compositions; genetic background, sizes of samples, population stratification, or selection of symptoms of disease between analyzed populations could explain these controversial results [52].

Additionally, our results indicate that the variant heterozygote CT and the homozygous TT of SNP -1615C > $\mathrm{T}$ of IFNG was associated with a decreased risk of CC. To our knowledge, this is the first study to show that the IFNG SNP rs2069705 was significantly associated with decreased risk of CC. Studies so far have only investigated this SNP in connection with the risk of breast cancer and SLE [53, 54]. Based on the evidence that the $\mathrm{T}$ allele is associated with a higher level of IFNG than the $\mathrm{C}$ allele the association of this SNP with this type of cancer is predictable, given that at breast cancer diagnosis, inflammatory cytokines are detected at elevated levels [54]. In contrast, a protective effect for the $\mathrm{T}$ allele in $\mathrm{CC}$ could be related to an increased expression of IFNG and play a role in protection against persistent HPV infection associated to CC development [55].

Nevertheless, a consensus seems to be emerging in that the combined effect of several cytokine SNPs may play a more crucial role in development disease. Thus, in order to explore whether the polymorphisms we examined could act together to increase risk for $\mathrm{CC}$, we combined alleles and tested the effect on risk for the combinations. Individuals carrying two or more of the risk-associated alleles (-590 (IL-4)/-573 (IL-6)/-592 (IL10)/-819 (IL-10)/-509 (TGFB1) were at increased risk for CC, compared to those with no risk-associated alleles. Although our study did not have the power to examine multiplicative interactions of specific genotypes, the combination of risk-associated alleles produced notably high odds ratios. This exploratory approach supported the idea that combinations of risk-associated alleles have an additive effect on the risk of CC.

In addition, we have found increased serum level of IL-4, IL-6, IL-10 and TGFB1 cytokines among our CC patients. Levels of IFNG were lower in the group of women with CC compared to controls. This is in accordance with previous works indicating a shift towards a T helper 2-type (Th2) cytokine pattern in CC [56] and that increased serum levels of IL-6, IL-10, and TGFB1 are associated with progression of $\mathrm{CC}$ during different stages, all of which have the potential to be angiogenic amplifiers [57].

Given that cytokines contribute importantly to each step of cancer development and progression, and that deregulated levels of cytokines and cytokine receptors can be detected in cancer patients locally and systemically [58], this study demonstrated an anti-inflammatory genetic profile, 
which is associated with increased susceptibility to cervical cancer. However, no statistically significant interactions were obtained between the polymorphisms cytokines of interest and respective serum levels.

IL-4 could possibly be exerting inhibitory effects on the expression and release of proinflammatory cytokines, IL-6 could be inducing prometastatic genes that subsequently lead to proliferation, and prolonged survival of cancer cells, given that the IL-6 serum levels are associated with poor prognosis [24]. Increased serum IL-10 levels could facilitate development of tumors by suppressing the expression of MHC class I and II antigens and preventing tumor antigen presentation to CD8cytotic $\mathrm{T}$ lymphocytes [31]. In addition to its immunosuppressive effects, IL10 can induce transcription of the HPV16 E7 oncoprotein [59]. Additionally, in one of our previous studies, systemic IL-10 mRNA expression level and the IL-10 protein level in serum are significantly higher in cervical lesions compared to women without lesions. We postulate that IL-10 and TGFB1 induce immune system evasion through an immunosuppressive state in the environment of the cervix in women infected with HPV [6].

Additionally, we are aware of a few limitations in our study, some of which cannot be overcame. First, -based in the patients and the control group randomly from the same hospital, we cannot completely rule out the inherent selection bias. Nevertheless, in order to minimize potential biases, we have made a rigorous epidemiological design of study subjects and more statistical adjustments for known risk factors. Second, our sample is medium sized, which may weaken the statistical power of this study. Under the current sample size, we have $99 \%$, $98 \%, 92 \%$ and $91 \%$ power at a 0.05 significance level to detect an OR of 1.2 or higher for -590 IL-4 and -1615 IFNG, for -592 IL-10 and -509 TGFB1, for -573 IL- 6 and for -819 IL-10 polymorphisms, respectively. However, well-designed large, prospective studies with detailed information about HPV infection are required to validate our findings and confirm this hypothesis.

\section{Conclusions}

In conclusion, our results suggest an association of three SNP's Th2 cytokines (IL-4, IL-6 and IL-10) and Th3 (TGFB1) cytokine with CC. Evaluating the association of the burden of risk alleles -590 (IL-4)/-573 (IL-6)/-592 (IL-10)/-819 (IL-10)/-509 (TGFB1) with CC, we found that carrying three or more risk alleles has an additive effect on the risk of CC. We demonstrate a significant difference in the level of serum proteins IL-4, IL-6, IL-10 and TGFB1 in cases compared to controls $(p<0.001)$. Thus, women with CC have an imbalance in the pattern of cytokines Th1/Th2 given systemically by an increase in type II cytokines (IL-4, IL-6 and IL-10, suppressor of the cellular immune response) and reduced in type I cytokine (INFG), allowing HPV persistence and development of lesions and CC. Finally, Significant associations found for SNP's -590 (IL-4)/- 573 (IL-6)/-592 (IL-10)/819 (IL-10)/-509 (TGFB1) with CC, indicate that these polymorphisms are potential candidates for predicting the risk of development of $\mathrm{CC}$, representing a risk allelic load for $\mathrm{CC}$ and can be used as a biomarker of susceptibility to this disease. These markers could be useful for early prevention programs and be clinically relevant as immunological biomarkers in patients with cervical lesions.

\section{Abbreviations}

CC: cervical cancer; Cl: confidence interval; ETS family proteins: E26 transformationspecific family proteins; GAPDH: glyceraldehyde-3-phosphate dehydrogenase; HPV: human papilloma virus; HR-HPV: high-risk human papillomavirus; IFNG: Interferon-gamma; IL-10: interleukin 10; IL-4: interleukin 4; IL-6: interleukin 6; MAF: minor allele frequency; mRNA: messenger RNA; $\mathrm{NCL}$ : non-cervical lesions; OR: odds ratio; PBMC: peripheral blood mononuclear cells; PCR: polymerase chain reaction; SNP: single nucleotide polymorphism; STD: sexually transmitted disease; TGFB1: transforming growth factor beta 1; Th: T helper cells; TNF: tumor necrosis factor.

\section{Acknowledgements \\ The authors wish to thank Juraj Lord for manuscript assistance. The authors wish to thank all CAPASAM members and the administrative personnel of INSP. This work was submitted in partial fulfillment of the requirements for the PhD. degree of Torres-Poveda KJ from the Doctoral Program in Public Health of the School of Public Health of Mexico. Torres-Poveda thanks the Ministry of Foreign Affairs of Mexico for the PhD fellowship.}

\section{Funding}

This work was supported by the Instituto Nacional de Salud Pública, Mexico and grants from Consejo Nacional de Ciencia y Tecnología (MX) CONACyT-FONSEC SSAVIMSS/ISSSTE-2008-C01-87701, CONACYT-Fondo E0013 APOYO COMPLEMENTARIO CATEDRAS-2014-C01-245520, CONACYT-FONSEC SSA/IMSS/ISSSTE-2014C01-234149 and CONACYT-Fondo APOYOS COMPLEMENTARIOS PARA LA ADQUISICIÓN DE EQUIPO CIENTÍFICO 2013-205707, Mexico.

\section{Availability of data and materials}

SNPS studied in this investigation were validated SNPs for frequency or for utilization in the HAPmap Project and SNPs reported in public SNPper.URL: http// snpper.chip.org. Likewise, the SNP_ID of each SNP are included in the Genotyping section within of the Methods section.

\section{Authors' contributions}

TPK participated in the design of the study, the collection of clinical materials, carried out the genotyping and cytokines analysis in serum, the statistical analysis and drafted the manuscript. BGAl participated in the design of the study and the statistical analysis. BRM participated in the cytokines analysis in serum. MMR and ZDMA participated in the processing of samples. LEG, DRK and CD participated in the selection of study population, gynecological sampler and patient care. PZO and BMVH participated in the analysis of the results. GCA and MMV participated in the analysis of the results and drafted the manuscript. All authors read and approved the final manuscript.

\section{Competing interests}

The authors declare that they have no competing interests.

\section{Consent for publication}

Not applicable.

\section{Ethics approval and consent to participate}

This study was conducted according to the principles expressed in the Declaration of Helsinki. It was approved by the Research, Ethics and Biosafety 
Committees at INSP (Cl814 and Cl1289 No. 1624) and INCan (INCan/CC/326/ 10CB/609). Written informed consent was obtained from all participants.

\section{Author details}

'Dirección de Infecciones Crónicas y Cáncer. Centro de Investigación sobre Enfermedades Infecciosas, Instituto Nacional de Salud Pública (INSP), (Chronic Infectious Diseases and Cancer Division. Center for Research on Infectious Diseases. National Institute of Public Health Mexico), Av. Universidad 655, Santa María Ahuacatitlán, Cuernavaca C.P.62100, Morelos, Mexico. ${ }^{2}$ CONACyT Research Fellow-Instituto Nacional de Salud Pública (INSP), Cuernavaca, Morelos, Mexico. ${ }^{3}$ Division of Basic Research, Instituto Nacional de Cancerología (INCan), SS. Mexico City, Mexico. ${ }^{4}$ Private Health Center for Gynecology, Cuernavaca, Morelos, Mexico. ${ }^{5}$ Centro de Atención para la Salud de la Mujer (CAPASAM), (Center for Women's Health). Health Services of the State of Morelos, Cuernavaca, Mexico. ${ }^{6}$ Division of Clinical Research, Instituto Nacional de Cancerología (INCan), SS. Mexico City, Mexico. ${ }^{7}$ Unit of Biomedical Research in Cancer, Instituto Nacional de Cancerología (INCan), SS and Biomedical Research Institute. Universidad Nacional Autónoma de México, Mexico City, Mexico.

Received: 17 July 2015 Accepted: 16 May 2016

Published online: 24 May 2016

\section{References}

1. Arbyn M, Castellsagué $X$, de Sanjosé S, Bruni L, Saraiya M, Bray F, et al. Worldwide burden of cervical cancer in 2008. Ann Oncol. 2011;22(12):2675-86.

2. INEGI. Estadísticas de mortalidad. Cubos dinámicos y CONAPO 2012. Proyecciones de la población de México 2012-2050. 2012.

3. Insinga RP, Perez G, Wheeler CM, Koutsky LA, Garland SM, Leodolter S, et al. Incident cervical HPV infections in young women: transition probabilities for CIN and infection clearance. Cancer Epidemiol Biomarkers Prev. 2011;20:287-96.

4. Conesa-Zamora P. Immune responses against virus and tumor in cervical carcinogenesis: treatment strategies for avoiding the HPV-induced immune escape. Gynecol Oncol. 2013;131(2):480-8.

5. Bermúdez-Morales VH, Gutierrez LX, Alcocer-Gonzalez JM, Burguete A, Madrid-Marina V. Correlation between IL-10 gene expression and HPV infection in cervical cancer: a mechanism for immune response escape. Cancer Invest. 2008;26(10):1037-43.

6. Torres-Poveda K, Burguete-García Al, Cruz M, Martínez-Nava GA, Bahena-Román M, Ortíz-Flores E, et al. The SNP at -592 of human IL-10 gene is associated with serum IL-10 levels and increased risk for human papillomavirus cervical lesion development. Infect Agent Cancer. 2012;7(1):32-40.

7. Basavaraju U, Shebl FM, Palmer AJ, Berry S, Hold GL, El-Omar EM, et al. Cytokine gene polymorphisms, cytokine levels and the risk of colorectal neoplasia in a screened population of Northeast Scotland. Eur J Cancer Prev. 2015;24(4):296-304.

8. Zhang X, Zhang L, Tian C, Yang L, Wang Z. Genetic variants and risk of cervical cancer: epidemiological evidence, meta-analysis and research review. BJOG. 2014;121(6):664-74

9. Muñoz N, Castellsagué X, de González AB, Gissmann L. Chapter 1: HPV in the etiology of human cancer. Vaccine. 2006;24 Suppl 3:S3/1-10.

10. Louie KS, de Sanjose S, Diaz M, Castellsagué X, Herrero R, Meijer CJ, et al. Early age at first sexual intercourse and early pregnancy are risk factors for cervical cancer in developing countries. Br J Cancer. 2009;100(7):1191-7.

11. Magnusson PK, Lichtenstein P, Gyllensten UB. Heritability of cervical tumours. Int J Cancer. 2000;88(5):698-701.

12. Alcocer-González JM, Berumen J, Taméz-Guerra R, Bermúdez-Morales V, PeraltaZaragoza O, Hernández-Pando R, et al. In vivo expression of immunosuppressive cytokines in human papillomavirus-transformed cervical cancer cells. Viral Immunol. 2006;19(3):481-91.

13. Díaz-Benítez CE, Navarro-Fuentes KR, Flores-Sosa JA, Juárez-Díaz J, UribeSalas FJ, Román-Basaure E, et al. CD3zeta expression and T cell proliferation are inhibited by TGF-beta1 and IL-10 in cervical cancer patients. J Clin Immunol. 2009;29(4):532-44.

14. Piersma SJ. Immunosuppressive tumor microenvironment in cervical cancer patients. Cancer Microenviron. 2011;4(3):361-75.

15. Torres-Poveda K, Bahena-Román M, Madrid-González C, Burquete-García Al, Bermúdez-Morales VH, Peralta-Zaragoza O, et al. Role of IL-10 and TGF- $\beta 1$ in local immunosuppression in HPV-associated cervical neoplasia. World J Clin Oncol. 2014;5(4):753-63.
16. Shamran HA, Hamza SJ, Yaseen NY, Al-Juboory AA, Taub DD, Price RL, et al. Impact of single nucleotide polymorphism in IL-4, IL-4R genes and systemic concentration of IL-4 on the incidence of glioma in Iraqi patients. Int J Med Sci. 2014;11(11):1147-53.

17. Tsai MH, Chen WC, Tsai CH, Hang LW, Tsai FJ. Interleukin-4 gene, but not the interleukin-1 beta gene polymorphism, is associated with oral cancer. J Clin Lab Anal. 2005;19(3):93-8.

18. Zheng Z, Li X, Li Z, Ma XC. IL-4 -590C/T polymorphism and susceptibility to liver disease: a meta-analysis and meta-regression. DNA Cell Biol. 2013;32(8):443-50.

19. Lim WY, Chen Y, Ali SM, Chuah KL, Eng P, Leong SS, et al. Polymorphisms in inflammatory pathway genes, host factors and lung cancer risk in Chinese female never-smokers. Carcinogenesis. 2011;32(4):522-9.

20. Castro FA, Haimila K, Sareneva I, Schmitt M, Lorenzo J, Kunkel N, et al. Association of HLA-DRB1, interleukin-6 and cyclin D1 polymorphisms with cervical cancer in the Swedish population-A candidate gene approach. Int J Cancer. 2009;125(8):1851-8.

21. Veerapaneni P, Kirma N, Nair HB, Hammes LS, Hall KL, Tekmal RR. Elevated aromatase expression correlates with cervical carcinoma progression. Gynecol Oncol. 2009:114:496-500

22. Wei LH, Kuo ML, Chen CA, Cheng WF, Cheng SP, Hsieh FJ, et al. Interleukin6 in cervical cancer: the relationship with vascular endothelial growth factor. Gynecol Oncol. 2001;82:49-56.

23. Shi TY, Zhu ML, He J, Wang MY, Li QX, Zhou XY, et al. Polymorphisms of the Interleukin 6 gene contribute to cervical cancer susceptibility in Eastern Chinese women. Hum Genet. 2013;132:301-12.

24. Grimm C, Watrowski R, Baumühlner K, Natter C, Tong D, Wolf A, et al. Genetic variations of interleukin-1 and -6 genes and risk of cervical intraepithelial neoplasia. Gynecol Oncol. 2011;121(3):537-41.

25. Bennermo M, Held C, Stemme S, Ericsson CG, Silveira A, Green F, et al. Genetic predisposition of the interleukin- 6 response to inflammation: implications for a variety of major diseases? Clin Chem. 2004;50(11):2136-40.

26. Kong SY, Lee HL, Eom HS, Park WS, Yun T, Kim HJ, et al. Reference intervals for circulating angiogenic cytokines. Clin Chem Lab Med. 2008;46(4):545-50.

27. Kingo K, Rätsep R, Kõks S, Karelson M, Silm H, Vasar E, et al. Influence of genetic polymorphisms on interleukin-10 mRNA expression and psoriasis susceptibility. J Dermatol Sci. 2005;37:111-3.

28. Ni J, Ye Y, Teng F, Wu Q. Interleukin 10 polymorphisms and cervical cancer risk: a meta-analysis. Int J Gynecol Cancer. 2013;23(1):126-33.

29. Steinke JW, Barekzi E, Hagman J, Borish L. Functional Analysis of -571 IL-10 promoter polymorphism reveals a repressor element controlled by Sp1. J Immunol. 2004;173:3215-22.

30. Stanczuk GA, Sibanda EN, Perrey C, Chirara M, Pravica V, Hutchinson IV, et al. Cancer of the uterine cervix may be significantly associated with a gene polymorphism coding for increased IL-10 production. Int J Cancer. 2001;94(6):792-4.

31. Ding $Q$, Shi $Y$, Fan B, Fan Z, Ding L, Li F, et al. The Interleukin-10 Promoter Polymorphism rs1800872 (-592C.A), Contributes to Cancer Susceptibility: Meta-Analysis of 16785 Cases and 19713 Controls. PLoS ONE. 2013:8(2):e57246.

32. Singh $H$, Jain M, Sachan R, Mittal B. Association of TNFA (-308G $>$ A) and IL-10 $(-819 \mathrm{C}>\mathrm{T})$ promoter polymorphisms with risk of cervical cancer. Int J Gynecol Cancer. 2009;19(7):1190-4.

33. Yu Z, Liu Q, Huang C, Wu M, Li G. The interleukin 10-819C/T polymorphism and cancer risk: a HuGE review and meta-analysis of 73 studies including 15,942 cases and 22,336 controls. OMICS. 2013;17(4):200-14

34. Xue H, Lin B, An J, Zhu Y, Huang G. Interleukin-10-819 promoter polymorphism in association with gastric cancer risk. BMC Cancer. 2012;12:102.

35. Wang J, Ding Q, Shi Y, Cao Q, Qin C, Zhu J, et al. The interleukin-10-1082 promoter polymorphism and cancer risk: a meta-analysis. Mutagenesis. 2012;27(3):305-12.

36. Rees L, Wood N, Gillespie K, Lai K, Gaston K, Mathieson P. The interleukin-10-1082 G/A polymorphism: allele frequency in different populations and functional significance. Cell Mol Life Sci. 2002;59(3):560-9.

37. Matsumoto K, Oki A, Satoh T, Okada S, Minaguchi T, Onuki M, et al. Interleukin-10-1082 gene polymorphism and susceptibility to cervical cancer among Japanese women. Jpn J Clin Oncol. 2010;40:1113-6.

38. Poli F, Nocco A, Berra S, Scalamogna M, Taioli E, Longhi E, et al. Allele frequencies of polymorphisms of TNFA, IL-6, IL-10 and IFNG in an Italian Caucasian population. Eur J Immunogenet. 2002;29:237-40. 
39. Barbisan G, Pérez LO, Contreras A, Golijow CD. TNF-a and IL-10 promoter polymorphisms, HPV infection, and cervical cancer risk. Tumor Biol. 2012;33:1549-56.

40. Shah R, Hurley CK, Posch PE. A molecular mechanism for the differential regulation of TGF-beta1 expression due to the common SNP -509C-T (c. -1347 C > T). Hum Genet. 2006;120(4):461-9.

41. Singh $\mathrm{H}$, Jain $\mathrm{M}$, Mittal B. Role of TGF-beta1 $(-509 \mathrm{C}>\mathrm{T})$ promoter polymorphism in susceptibility to cervical cancer. Oncol Res. 2009;18(1):41-5.

42. Ramos-Flores C, Romero-Gutiérrez T, Delgado-Enciso I, Maldonado GE, Plascencia VM, Vazquez-Vuelvas OF, et al. Polymorphisms in the genes related to angiogenesis are associated with uterine cervical cancer. Int J Gynecol Cancer. 2013;23(7):1198-204.

43. Liu L, Yang X, Chen X, Kan T, Shen Y, Chen Z, et al. Association between TNF-a polymorphisms and cervical cancer risk: a meta-analysis. Mol Biol Rep. 2012;39:2683-8.

44. Ding B, Fu S, Wang M, Yue C, Wang W, Zhou D, et al. Tumor necrosis factor a -308 G > A polymorphisms and cervical cancer risk: a meta-analysis. Int J Gynecol Cancer. 2012;22(2):213-9.

45. Pan F, Tian J, Ji CS, He YF, Han XH, Wang Y, et al. Association of TNF-a-308 and -238 Polymorphisms with Risk of Cervical Cancer: A Meta-analysis. Asian Pac J Cancer Prev. 2012;13(11):5777-83.

46. Jin Y. Association of Single Nucleotide Polymorphisms in Tumor Necrosis Factor-Alpha with Cervical Cancer Susceptibility. Cell Biochem Biophys. 2015;71(1):77-84.

47. Zhang H-L, Zhang YJ. A systemic assessment of the association between tumor necrosis factor alpha 308G/A polymorphism and risk of cervical cancer. Tumor Biol. 2013;34(3):1659-65.

48. Stanczuk GA, Sibanda EN, Tswana SA, Bergstrom S. Polymorphism at the -308promoter position of the tumor necrosis factor-alpha (TNF-alpha) gene and cervical cancer. Int J Gynecol Cancer. 2003;13:14853.

49. Govan VA, Constant D, Hoffman M, Williamson AL. The allelic distribution of -308 Tumor Necrosis Factor-alpha gene polymorphism in South african women with cervical cancer and control women. BMC Cancer. 2006:6:24.

50. Ivansson EL, Magnusson JJ, Magnusson PK, Erlich HA, Gyllensten UB. MHC loci affecting cervical cancer risk: distinguishing the effects of HLA-DQB1 and nonHLA genes TNF, LTA, TAP1 and TAP2. Genes Immun. 2008;9(7):613-23.

51. Calhoun ES, McGovern RM, Janney CA, Cerhan JR, Iturria SJ, Smith DI, et al. Host genetic polymorphism analysis in cervical cancer. Clin Chem. 2002; 48(8):1218-24.

52. Baena A, Leung JY, Sullivan AD, Landires I, Vasquez-Luna N, Quiñones-Berrocal J, et al. TNF-alpha promoter single nucleotide polymorphisms are markers of human ancestry. Genes Immun. 2002;3:482-7.

53. Kim K, Cho SK, Sestak A, Namjou B, Kang C, Bae SC. Interferon-gamma gene polymorphisms associated with susceptibility to systemic lupus erythematosus. Ann Rheum Dis. 2010;69(6):1247-50.

54. Li CJ, Dai Y, Fu YJ, Tian JM, Li JL, Lu HJ, et al. Correlations of IFN- $\gamma$ genetic polymorphisms with susceptibility to breast cancer: a meta-analysis. Tumour Biol. 2014;35(7):6867-77.

55. Song SH, Lee JK, Lee NW, Saw HS, Kang JS, Lee KW. Interferon-gamma (IFN-gamma): a possible prognostic marker for clearance of high-risk human papillomavirus (HPV). Gynecol Oncol. 2008;108(3):543-8.

56. Lages EL, Belo AV, Andrade SP, Rocha MÂ, de Freitas GF, Lamaita RM, et al Analysis of systemic inflammatory response in the carcinogenic process of uterine cervical neoplasia. Biomed Pharmacother. 2011;65(7):496-9.

57. Ali KS, Ali HY, Jubrael JM. Concentration levels of IL-10 and TNFa cytokines in patients with human papilloma virus (HPV) DNA ${ }^{+}$and DNA ${ }^{-}$cervical lesions. J Immunotoxicol. 2012:9(2):168-72

58. Chechlinska M, Kowalska M, Kaminska J. Cytokines as potential tumour markers. Expert Opin Med Diagn. 2008;2(6):691-711

59. Arany I, Grattendick KG, Tyring SK. Interleukin-10 induces transcription of the early promoter of human papillomavirus type 16 (HPV16) through the 5'-segment of the upstream regulatory region (URR). Antiviral Res. 2002;55(2):331-9.

\section{Submit your next manuscript to BioMed Central and we will help you at every step:}

- We accept pre-submission inquiries

- Our selector tool helps you to find the most relevant journal

- We provide round the clock customer support

- Convenient online submission

- Thorough peer review

- Inclusion in PubMed and all major indexing services

- Maximum visibility for your research

Submit your manuscript at www.biomedcentral.com/submit
Biomed Central 